'Universidade Federal do Paraná,

Departamento de Ciências Sociais, Brasil

simonemeucci2oro@gmail.com

Simone Meucci'

\title{
GILBERTO FREYRE NO COMANDO DO CENTRO REGIONAL DE PESQUISAS EDUCACIONAIS DO RECIFE: EDUCAÇÃO EM DEBATE (1957 - 1964)
}

Este trabalho nasceu do interesse em compreender as condições de produção e circulação das ideias de Gilberto Freyre nos anos de I950 e I960. Neste período, no Brasil, Freyre atuou em três frentes: a) elaborou textos para jornais e periódicos de grande circulação: destacamos em particular a publicação semanal, desde I948, de suas colunas na revista O Cruzeiro cuja tiragem, em I960, chegou a um milhão de cópias por semana (Abreu, 2008: 2I8); b) publicou livros completos - Quase política (1950), Um brasileiro em terras portuguesas e Aventura e rotina (1953), Integração portuguesa nos trópicos (1958), Ordem e progresso (1959), O velho Félix e A propósito dos frades (I959), Brasis, Brasil, Brasília (I968), além de rever sistematicamente seus textos antigos para novas reedições); c) orientou atividades na Fundação Joaquim Nabuco e no Centro Regional de Pesquisas Educacionais do Recife.

Deste conjunto de esforços, as atividades do Centro Regional de Pesquisas Educacionais do Recife são as menos conhecidas. Isso ocorre a despeito de haver, desde os anos de I980, um crescimento do interesse pelas análises dos Centros de Estudos Educacionais. São numerosos os estudos acerca das atividades dos Centros, realizados menos por sociólogos do que pesquisadores da área de educação (Cunha, I99I; Correa, I989; Freitas, 200I; Gonçalves, I996; Gouveia, 2008; Mariani, I982; Neves, 2002; Paoli, I995; Xavier, 1999). Esta bibliografia, ainda que não ignore o Centro do Recife, analisa em especial o Centro Brasileiro e os Centros Regionais do Rio de Janeiro, São Paulo e Minas Gerais. 
Com efeito, constatada a ausência de estudos sistemáticos sobre o Centro do Recife, decidimos investigá-lo do ponto de vista do Pensamento Social Brasileiro, na esperança de compreender aspectos relevantes da atuação de Gilberto Freyre no período, especialmente sua posição acerca no debate educacional da época.

Esta análise está relacionada a duas tendências da atual agenda de pesquisas em Pensamento Social Brasileiro. A primeira diz respeito ao interesse não apenas pelo estudo de intelectuais à "margem do cânone", mas também pela análise de autores "canônicos" de modo novo. Trata-se de identificar, nos intelectuais consagrados cujas grandes obras já foram tema de pesquisa, escritos e ações menos conhecidos a fim de reconstituir em toda a complexidade sua trajetória, interesses e dilemas, reconhecendo contextos e objetos de ação capazes de fazer ver nuances e articulações sofisticadas entre intelectuais, conhecimento e sociedade.

A segunda tendência do Pensamento Social Brasileiro, a qual esta proposta de análise está relacionada, diz respeito ao interesse sobre os anos de I950, cujos dilemas são agora especialmente notáveis. Parece que revolver o solo semeado pelos intelectuais brasileiros dos anos de I950 possibilita a elaboração de um inspirador "estado da arte", um balanço acerca da fortuna intelectual do período, além da compreensão da artesania de ideias e do processo de formulação de alternativas históricas anteriores a interrupção da experiência democrática.

Neste estudo demonstraremos uma dimensão deste contexto, considerando que o tema da educação nos anos de 1950 foi como uma espécie de dobradiça que tensionou o pacto federativo, as percepções sobre passado e futuro, Estado e sociedade.

As relações de Freyre com a educação são discretas, mas estão na origem de sua carreira de cientista social. Em I929, o pernambucano assumiu as aulas de sociologia na Escola Normal de Pernambuco, onde propôs um programa de pesquisas que reivindicava das futuras professoras um olhar atento aos efeitos do progresso e uma atuação em favor de um acordo entre tradição e modernidade (Meucci, 20I5). Neste artigo veremos como, depois de quase um quarto de século, Freyre retoma, num momento decisivo para definição da ossatura do sistema escolar brasileiro, tarefas para formação de professores e elaboração de pesquisas no campo da educação.

Para esta análise consultamos documentos do Centro do Recife, preservados na forma de microfilmes pela Fundação Joaquim Nabuco. São relatórios de atividades, prestações de contas e ofícios do período compreendido entre os anos de I958 e I964. ${ }^{I}$ Consultamos também os Cadernos Região e Educação, veículo de divulgação das atividades do Centro, em particular os números publicados entre os anos de I96I e ig68. 


\section{O CENTRO BRASILEIRO DE PESQUISAS EDUCACIONAIS}

O Centro do Recife foi um dos "braços" do Centro Brasileiro de Estudos Educacionais (CBPE), órgão do Instituto Nacional de Estudos Pedagógicos (INEP), subordinado ao Ministério de Educação e Cultura, criado em I955 por Anísio Teixeira (então diretor do INEP) com apoio da Unesco.

Os Centros Regionais eram subordinados ao CBPE, organizados segundo planos de trabalho aprovados após avaliação da comissão do INEP, executados sob regime de financiamento especial e convênios com governos ou entidades públicas ou privadas. Além de Pernambuco, os Estados de Minas Gerais, Rio de Janeiro, Rio Grande do Sul e Bahia também receberam sedes regionais do CBPE. O Centro e suas unidades regionais foram reconhecidos por seu estímulo à pesquisa na área das Ciências Sociais numa época em que as modalidades de financiamento e qualificação profissional no campo das pesquisas sociais eram bastante escassas.

Todos os Centros tinham uma Divisão de Estudos Educacionais (referidos à escola) e uma Divisão de Estudos Sociais (referidos à sociedade em seu caráter mais amplo). A criação das duas divisões se fundamenta na ideia de que pesquisas educacionais e sociológicas são indissociáveis para elaboração de uma nova política educacional capaz de ajustar-se às exigências do desenvolvimento social e cultural das diversas regiões do país.

A criação do CBPE e dos Centros Regionais está relacionada à tramitação de um projeto para a definição da Lei de Diretrizes e Bases da Educação Brasileira (LDB). No período entre o final da década de I940 e a primeira metade dos anos 1950 o debate teve como protagonistas Clemente Mariani (filiado à União Democrática Nacional - UDN, Ministro da Educação e Saúde entre os anos de I946 e I950) e Gustavo Capanema (então Deputado Federal pelo Partido Social Democrático - PSD). Mariani apresentou Anteprojeto para a LDB que recebeu parecer desfavorável de Capanema, fato que levou à suspensão da tramitação até I952, quando sua retomada conduziu a uma severa discussão sobre o legado do Estado Novo no campo educacional (Ferreira, 2006: 59). O impasse dizia respeito ao ensino secundário. No anteprojeto original cada estado deveria organizar seu sistema de ensino respeitando certos princípios gerais elaborados pela União. Capanema condenava a proposta de descentralização argumentando que se tratava de uma ameaça à qualidade de ensino e, no limite, à própria ideia de nação (Montalvão, 20II: I34).

Este impasse tomava forma no mesmo ano em que Anísio Teixeira assumiu a direção do INEP. Teixeira foi personagem ativo no debate parlamentar, manifestou-se favorável à descentralização administrativa, financeira e curricular entendendo a "diversificação" como um sintoma do desenvolvimento cultural da nação (Teixeira, I953). Para Teixeira, estava em jogo a possibilidade superação da ossatura institucional do Estado Novo e o 
ressurgimento do federalismo como um instrumento de administração pública (Montalvão, 20II: I22). Nesse sentido, entendemos que a criação dos Centros Regionais coordenados pelo CBPE e a pretensão de investigar coordenadamente as realidades socioeducacionais regionais é proposta que expressa uma posição nesta controvérsia. Os Centros Regionais pareciam espelhar a descentralização política e financeira do sistema educacional desejada por Anísio Teixeira (Ferreira, 2006: 78).

\section{O CENTRO DO RECIFE}

O Centro Regional de Pesquisas Educacionais do Recife foi criado por meio de portaria do INEP em 3 de outubro de $1957 .{ }^{2}$ Freyre assumiu a direção alguns dias após sua criação ${ }^{3}$ e, em novembro, iniciou as atividades em uma cerimônia que reuniu Anísio Teixeira, os governadores de Pernambuco, Paraíba e do Rio Grande do Norte (áreas de atuação do Centro), o prefeito do Recife, reitores da Universidade Federal Rural de Pernambuco e da Universidade Católica, além de autoridades militares.

A aceitação deste cargo e de suas responsabilidades num momento em que a carreira de Freyre se internacionalizava pode estar relacionada com a afinidade entre os fundamentos da criação do CBPE e dos Centros Regionais e as ideias do autor. No discurso de posse do Centro Regional do Recife, Freyre reivindica uma forma de educação escolar capaz de se adequar às diferentes formas de vida regionais, ${ }^{4}$ o que nos leva a identificá-lo como parceiro de Teixeira na luta pela descentralização do sistema de ensino.

Com efeito, o que parece ligar Freyre e Teixeira é a contraposição aos ideais de Capanema, agente político que impedia a tramitação da LDB em defesa de uma política nacional centralizadora para a educação no Brasil. Este não é o primeiro episódio em que os destinos de Teixeira, Freyre e Capanema estão cruzados. Capanema foi, em 1939, protagonista do fechamento da Universidade do Distrito Federal (UDF), instituição idealizada por Anísio Teixeira que teve Gilberto Freyre como um de seus professores e principais apoiadores (Meucci, 20I5). A nova parceria entre Freyre e Teixeira, quase vinte anos após o encerramento da UDF, parece colocá-los novamente em confronto com Capanema.

Embora a portaria de criação do Centro tenha se referido ao Centro Regional de Pesquisas Educacionais de Pernambuco, em todas as correspondências oficiais posteriores a instituição é chamada de Centro de Pesquisas Educacionais do Recife. Segundo Gôuvea (2008: I75), foi o único Centro Regional cuja denominação fazia referência à cidade que o abrigava. É possível que a renomeação tenha sido uma solicitação do próprio Freyre a fim de destacar o nome da cidade, pois entendia as atividades do Centro como uma oportunidade de recuperar o papel do Recife como "capital intelectual de uma região inteira". ${ }^{5}$ 
O Centro Regional do Recife foi instalado no edifício do Instituto Joaquim Nabuco, que também cedeu equipamentos e materiais de consumo para o início das atividades. ${ }^{6}$ Mas, para abrigar o Centro em lugar independente, já no final de 1957, logo após a inauguração, Freyre encaminhou a Anísio Teixeira proposta de compra de um terreno ao lado do Instituto.7 O imóvel foi adquirido pelo INEP em I958 e tinha uma área construída de $673 \mathrm{~m}^{2}$, onde foi instalado o Centro Regional. ${ }^{8}$ Ao longo de 1962, neste terreno, foi construída uma Escola Experimental. Fontes consultadas indicam ainda que, em I960 foi adquirido novo terreno vizinho ao Centro para a construção de um auditório. 9 Em 1975, com o definitivo encerramento das atividades do Centro, ${ }^{\text {Io }}$ o Instituto Joaquim Nabuco herdou os terrenos e prédios, móveis, funcionários e a biblioteca com cerca de sete mil volumes (Freston, 1989: 336).

Durante o período de seu funcionamento as atividades do Centro foram as seguintes: a) desenvolvimento de pesquisas sociais e educacionais; b) oferta de cursos e seminários; c) gestão da Escola Experimental primária e de uma biblioteca; e d) manutenção de um periódico para divulgação dos resultados dos trabalhos.

No início do seu funcionamento, o Centro contava com sete funcionários administrativos que executavam os serviços da Secretaria Executiva e da Biblioteca. ${ }^{\text {II }}$ Em 1959, notamos crescimento do quadro, já que constam onze funcionários responsáveis pela organização dos serviços (entre datilógrafos, motorista, secretárias, faxineiro, contínuo). ${ }^{\mathrm{I2}} \mathrm{Em}$ I975, segundo Freston (I989: 336), o Centro contava com vinte funcionários em sua folha de pagamento. Houve diversas modalidades de vínculo de trabalho: técnicos e pesquisadores contratados por tempo limitado, professores emprestados da Secretaria de Educação e da Prefeitura e, após 1962, técnicos administrativos convertidos em funcionários públicos federais estáveis.

O organograma espelhava o do CBPE e era constituído pela Direção Geral (que sempre foi ocupada por Gilberto Freyre), pela Divisão de Estudos e Pesquisas Educacionais (DEPE) e Divisão de Estudos e Pesquisas Sociais (DEPS) (cada uma composta por um diretor, um assistente e seus respectivos técnicos) e pela Secretaria Executiva (composta pelo corpo de funcionários administrativos). No ano de I96o foi criada uma nova Divisão, dedicada ao Aperfeiçoamento do Magistério (DAM) a qual esteve ligada, a partir de I963, a Escola Experimental de nível primário.

O primeiro diretor da DEPE foi Joaquim Moreira de Sousa, indicado pelo INEP para orientar, de início, as atividades técnicas do Centro. Ocupou o cargo até maio de I958 quando foi substituído por Carlos Frederico Maciel, um dos pesquisadores mais estáveis do Centro, que ficou no cargo de vice-diretor geral (ao lado de Gilberto Freyre) e na direção da DAM. Entre os que assumiram a função de assistentes da DEPE figuram: Paulo Silveira Rosas (fevereiro de I960 a março de I96I), Zaida Maria Cavalcanti (desde agosto 
de I961 até I966), Israel Guimarães Cardoso (de fevereiro de I963 até dezembro de ig63).

O primeiro diretor do DEPS foi o próprio Gilberto Freyre, que permaneceu no cargo até I959, quando foi substituído por Levy Porfírio da Cruz ${ }^{13}$ (de janeiro de I959 até dezembro de I962). No período de I959 até I962 foi assistente do DEPS José Geraldo da Costa. Em I962, Gilberto Freyre assumiu novamente a direção do DEPS, sendo apoiado por Miriam Brindeiro Moraes de Vasconcelos e Tarcízio do Rego.

A DAM foi dirigida, no seu início, por Carlos Frederico Maciel, que foi substituído por Maria Graciela Peregrino. Entre suas assistentes figuram M. de Jesus Albuquerque e Janise Pinto Peres, professora da rede pública de ensino do Estado de Pernambuco colocada à disposição do Centro. Trabalharam também na DAM professoras ex-bolsistas do INEP (que foram estudar na Universidade de Indiana, nos EUA, e que, em contrapartida, prestaram serviços ao Centro): Maria Luiza de Melo, Marcionila Rand, Marlene Medeiros e Ivanise Rebello. Foram ainda colocadas à disposição do DAM as professoras da rede pública de Pernambuco Maria de Lourdes Costa Barros, Heysa Costa e Dinara Leite.

O Centro do Recife publicou ainda um periódico, a revista Cadernos Região e Educação, cujo primeiro número foi lançado em I96I. ${ }^{\mathrm{I} 4} \mathrm{~A}$ iniciativa estava relacionada a uma orientação geral do CBPE para constituição de um conjunto de publicações sobre estudos socioeducacionais no Brasil. ${ }^{15}$

As tensões relativas à organização e à manutenção do Centro do Recife diziam respeito a aspectos inerentes à articulação entre os Centros Regionais e o CBPE. Documentos consultados sugerem que era grande o desafio de organizar, do ponto de vista administrativo e científico, as atividades dos diversos Centros Regionais. Possíveis dificuldades nesse sentido podem ser fundamento das mudanças no organograma do CBPE ocorrida em I957, época da criação do Centro do Recife. Foram então criados o Conselho Deliberativo e, num nível inferior do organograma, a Coordenação de Planejamento. O Conselho Deliberativo tinha função científica, ao passo que a Coordenação de Planejamento articulava, do ponto de vista financeiro e organizacional, as diferentes instâncias.

Segundo o novo organograma, a avaliação e aprovação dos planos e métodos de trabalhos elaborados pelos Centros Regionais eram realizadas pelo Conselho Deliberativo, composto pelos seguintes membros: diretor do INEP, representante da Unesco e coordenadores das Divisões de Estudos Educacionais e Estudos Sociais do CBPE. Nesse sentido, os Centros Regionais submetiam seus projetos ao CBPE. A Comissão Consultiva - composta pelo diretor do INEP, membros do Conselho Deliberativo e representantes dos Conselhos Regionais - era a instância superior dedicada a elaborar normas e propor alternativas para a articulação dos trabalhos entre os Centros Regionais e o Centro Brasileiro, e cujos membros se reuniam duas vezes por ano. 
Interessante observar que no novo organograma, Anísio Teixeira ocupava três posições: era, a um só tempo, diretor do INEP, membro da Comissão Consultiva e membro do Conselho Deliberativo. Parecia ser responsável por um elevado número de tarefas e concentrar grande poder. Na documentação analisada, observamos, com efeito, que o diretor do INEP acompanhava em detalhes o que ocorria nos Centros Regionais: se responsabilizava por unificar métodos e modelos de estudo do professorado dos diferentes Centros, ${ }^{16}$ ao mesmo tempo em que tentava justificar medidas do engenheiro relativas à definição das cores da pintura da Escola Experimental da qual Freyre parecia discordar. ${ }^{17}$ Nesse sentido, ainda que houvesse inspiração na descentralização, em termos práticos o Centro parecia atuar de modo bastante centralizado.

Uma dificuldade dos Centros Regionais parecia ser o orçamento. O "plano de contas" era definido no início de cada ano tendo em vista as atividades aprovadas. A distribuição de verbas pretendia atender as diferentes divisões dos Centros com prioridade para as atividades científicas. Nesse sentido, devido à escassez de recursos, Anísio Teixeira apelava aos diretores do Centro para que não sacrificassem o "setor científico" com as despesas gerais de administração. ${ }^{18}$ No entanto, como veremos, foi difícil manter as atividades de pesquisa.

A despeito dessa dificuldade, o Centro Regional do Recife foi dos mais ativos. Gouvêa (2008: 20I2) atribui seu dinamismo às parcerias com a Aliança para o Progresso, por exemplo. ${ }^{19}$ Ao consultar os documentos, constatamos que, de fato, a Aliança para o Progresso se apresenta como uma das mais significativas instituições de apoio ao Centro a partir de 1962. Possivelmente esse apoio tinha sua origem no acordo de cooperação financeira e técnica, firmado entre a Agência dos Estados Unidos para o Desenvolvimento Internacional (USAID) e a Superintendência do Desenvolvimento do Nordeste (Sudene), para o desenvolvimento daquela Região. ${ }^{20}$ Este acordo explicaria algumas atividades comuns da Sudene e do Centro do Recife, em especial o "Ciclo de Sessões de Estudo sobre Documentos da Conferência de Santiago", ocorrido entre agosto e outubro de 1962, quando ambas as instituições se reuniram para discutir os documentos produzidos durante a Conferência sobre Educação e Desenvolvimento Econômico e Social na América Latina, ${ }^{21}$ realizada em Santiago do Chile no mesmo ano. ${ }^{22}$ É provável que esta discussão fosse dedicada a um levantamento acerca das possibilidades de implementação de um projeto educacional que favorecesse o desenvolvimento econômico regional, conforme as orientações da Aliança para o Progresso.

Além do acordo com a Sudene, é também possível que alguns recursos da USAID chegassem ao Centro do Recife por meio de acordos diretos com os governos de estado das áreas de atuação do Centro. ${ }^{23}$ Esses acordos previam, além de ações de combate à fome, o desenvolvimento regional através de intervenções nas áreas de infraestrutura, saúde, habitação e educação. Em par- 
ticular no campo da educação, previu-se a construção de escolas, formação de professores e alfabetização (Ribeiro, 2006: 42).

Sabe-se, por exemplo, que Cid Sampaio, que esteve à frente do Estado de Pernambuco entre 1959 e I963, aceitou investimentos internacionais para o campo educacional (Barbosa, 2010: 40). A propósito, em I963, o mais conhecido experimento do método Paulo Freyre foi financiado pela Aliança para o Progresso, num acordo dessa natureza com o governo do Estado do Rio Grande do Norte, área de ação do Centro do Recife.

Nesse sentido, pode-se afirmar que o Centro do Recife foi favorecido pelo fato de o governo estadunidense considerar o Nordeste uma área potencialmente vulnerável à expansão da ideologia comunista e, por isso, investir na região recursos através da USAID para o cumprimento das metas definidas pela Aliança para o Progresso. Com isso, a despeito das dificuldades, tornou-se um dos Centros mais dinâmicos, conforme veremos a seguir.

\section{A AGENDA DE PESOUISAS}

A partir da consulta às fontes, foi possível identificar a agenda de pesquisas do Centro do Recife. No DEPE, houve investigações de diagnóstico da educação no Nordeste (desde os cursos primários até o superior), tanto do ponto de vista dos conteúdos escolares quanto das questões relativas à administração, recursos; padrão de vida, expectativas de carreira e seleção dos alunos; além da condição de trabalho e vida do docente. Predominaram pesquisas em Pernambuco, embora a área de abrangência do Centro se referisse também aos demais estados ao norte da Região. A partir de I962 foram frequentes as pesquisas quantitativas mais abrangentes, especialmente sobre os indicadores de evasão escolar. Houve outras pesquisas dedicadas à elaboração de programas de ensino primário adaptados às necessidades culturais de cada contexto, demarcação de perfis econômicos e culturais das áreas do Nordeste para orientar a formulação do plano nacional de educação, definições de critérios para orientação profissional e até a experiência de implantação de um programa de televisão de ensino de inglês.

Na DEPS, as pesquisas se dedicavam a perscrutar formas não escolares de educação e transmissão de ideias. Houve estudos de poetas populares e da literatura infantil e juvenil, estudos de comunidades de jangadeiros e de pequenos municípios rurais (Timbaúba), tipificação de estruturas familiares e análise de métodos de castigo e recompensa familiares. 
Muitos trabalhos do DEPS não foram concluídos. O de Paulo Freire sobre "Vocabulário infantil de crianças de 7 a I 2 anos em Pernambuco", proposto em I958, teve seu desenvolvimento interrompido por sugestão do CBPE. O de Levy Cruz, "Mobilidade espacial e estrutura social em pequenas comunidades do Nordeste", dedicado ao recenseamento e aplicação de questionários em comunidades nordestinas do Sertão, Agreste e Zona da Mata também parece não ter sido concluído. Nos relatórios do CBPE consta também outro projeto, elaborado por Levy Cruz, para o estudo do município de Timbaúba, que não foi concluído. ${ }^{24}$

Essa intermitência das pesquisas do DEPS, notável especialmente a partir dos anos de I960, tem relação com dificuldades para a estabilização do quadro de pesquisadores. As pesquisas, no início das atividades do Centro, foram realizadas por colaboradores contratados para esta finalidade. Não obstante, no decorrer dos anos, são os diretores das Divisões e seus assistentes os únicos protagonistas da atividade investigativa do Centro.

Dois dos mais experientes pesquisadores deixaram o Centro entre os anos de I96I e I962. Em I96I, Paulo Rosas - da DEPE - se afastou do Centro para iniciar as atividades no Movimento de Cultura Popular (MCP), ${ }^{25}$ organizado pelo recém-eleito prefeito do Recife, Miguel Arraes. O sociólogo Levy Cruz se afastou do Centro no final do ano de 1962 para assumir funções no Instituto de Ciências do Homem da Universidade do Recife, atualmente Universidade Federal de Pernambuco. Seu desligamento foi recebido com lamento por Anísio Teixeira ${ }^{26}$ que reconhecia, porém, que o Centro do Recife, devido às dificuldades impostas ao INEP, não teria condições de manter pesquisadores qualificados no seu quadro competindo com instituições que ofereciam trabalho estável e melhor remunerado. ${ }^{27}$

Textos publicados no Cadernos Região e Educação, periódico do Centro, confirmam, com efeito, redução no quadro de pesquisadores. Em I963 figuram apenas dois autores responsáveis por todo o conteúdo do periódico: Carlos Frederico Maciel e Myriam Brindeiro de Moraes Vasconcelos. ${ }^{28} \mathrm{O}$ mesmo se repete em 1964, quando Gonçalves Fernandes e, mais uma, vez Myriam Brindeiro de Moraes Vasconcelos assinam todos os textos. ${ }^{29}$

A redução das pesquisas sociais e a falta de interesse dos pesquisadores em permanecer no Centro do Recife são fenômenos que estavam, no entanto, relacionados a uma mudança de orientação do Centro Brasileiro a partir de I962. Neste ano, foram encerradas as atividades de pesquisa da Divisão de Estudos e Pesquisas Sociais do CBPE, transformada em Comissão para o Planejamento da Educação (COPLED), responsável pela elaboração de um Plano Nacional para Educação. Tudo leva a crer, conforme tese de Ferreira (2006), que a partir de I962, a agenda de pesquisas se altera significativamente, respondendo não mais aos debates relacionados à LDB (que afinal fora aprovada em dezembro de I96I), mas às demandas do Conselho Nacional de 
Educação responsável pela elaboração do Plano Nacional de Educação. No caso do Recife, esse foi também, conforme vimos, o período de aumento dos recursos através do apoio da Aliança para o Progresso (Ferreira, 2006: 205). Possivelmente, recursos chegaram mais facilmente ao Centro, mas ao preço do sacrifício da abordagem sociológica.

Interessante observar, na correspondência entre Freyre e Teixeira, que há certa tensão que se agrava em I962, ano de conclusão das obras da Escola Experimental. Ofícios sugerem que a administração do Centro ficou mais difícil. Há frequentes pedidos de recursos, atrasos nos relatórios de prestação de contas,,$^{30}$ apelos diante da dificuldade de manter os pesquisadores com baixos salários. ${ }^{31}$ Esta tensão parece contradizer Peregrino (I987), que afirma, em seu relato, que após a criação da Escola Experimental, no ano de I963, Freyre teria ficado mais tranquilo na medida em que verbas seriam concedidas com menos restrições. De fato, é possível que a Escola Experimental, bem como as pesquisas aplicadas, fossem a solução para a sobrevivência material do Centro. Entretanto, o motivo original que impulsionou Freyre para a direção do Centro não encontrava mais formas de sustentação: a pesquisa sociológica.

\section{OS CURSOS DE APERFEIÇOAMENTO E A ESCOLA EXPERIMENTAL}

Ao mesmo tempo em que observamos a limitação das pesquisas sociais, houve ampliação das atividades da DAM. Pela natureza de suas atividades, a DAM teve a possibilidade de gerir cursos através de professores cedidos pelo governo do Estado. A Escola Experimental estava também ligada à DAM e contava, em seus quadros, com professores cedidos pela Prefeitura. Nesse sentido, o crescimento notado ao longo dos anos no corpo administrativo pode ser explicado devido à ampliação das atividades que exigiam o suporte operacional da Secretaria, como a Escola Experimental, a Biblioteca e os cursos de formação do magistério.

Tudo leva a crer que nos anos de 1962 e I963 as atividades relativas a seminários e cursos de formação se tornaram mais intensas. É possível ao menos lançar a hipótese de que estes cursos têm menos um caráter de testar e discutir resultados de investigações, do que o propósito de difundir certas técnicas e ferramentas de ensino. Os cursos instruíam sobre a administração escolar, o uso de recursos didáticos e técnicas artísticas para alfabetizar crianças. Houve ainda dois cursos de sociologia da família que ocorreram no final dos anos de I950.

Da relação de cursos, consideramos interessante destacar um que foi oferecido logo no início das atividades do Centro, dedicado à formação de pesquisadores sociais. Possivelmente este curso está associado às dificuldades relativas à falta de pesquisadores na área de ciências sociais e educação. 
Observamos também a oferta de cursos para a língua inglesa entre os professores. É provável que alguns deles tenham recebido bolsas de estudos para estudar nos Estados Unidos, considerando o interesse dos daquele país na difusão de seu ideário no contexto da Guerra Fria. Constatou-se ainda a oferta de um curso de alemão para os técnicos do próprio Centro, o que pos sivelmente está relacionado ao desejo de Freyre de unir, por meio de intercâmbio, o Centro do Recife, o Instituto Joaquim Nabuco e a Universidade de Münster. Neste período, Gilberto Freyre se aproximava do sociólogo alemão Helmut Schelsky, episódio que deu origem a dois Colóquios Teuto-Brasileiros, o primeiro em 1963 (sediado em Porto Alegre) e o segundo em I968 (sediado nas dependências do Centro, no Recife) (Peregrino, 1987).

No entanto, a maior atividade da DAM foi a Escola Experimental de educação primária. Um relatório publicado no Cadernos Região e Educação nos permite reconhecer, se não as atividades, o perfil dos alunos da Escola, que fora inaugurada em I de agosto de 1963, com Io6 estudantes matriculados. A pretensão era atender 180 alunos distribuídos em turmas com no máximo 30 crianças. O prédio tinha seis salas de aula, uma biblioteca, um auditório e uma praça de recreio. A equipe da escola era constituída por professores selecionados a partir do quadro docente da Secretaria de Educação de Pernambuco. ${ }^{32}$

O estudo descrito na revista pretendia orientar a implementação de campanhas para melhorar as condições de vida e, por conseguinte, o aproveitamento escolar dos alunos. É constituído por sondagens sobre a renda familiar, condições de habitação, composição da família e escolaridade de seus membros, formas de lazer e religião, bem como o nível de satisfação dos pais com a Escola. As crianças moravam em bairros vizinhos num raio máximo de $2,5 \mathrm{~km}$ de distância. A média de renda da família era de I a 3 salários mínimos e os pais eram, em sua maioria, analfabetos e semianalfabetos. O estudo conclui que seriam necessárias ações educacionais urgentes para alertar sobre os perigos da água poluída, sobre o uso adequado do sanitário e o valor nutricional dos alimentos. O relatório também sugere - já que o estudo demonstra que a maioria das casas possui máquinas de costura - a oferta de cursos de corte e costura e aponta a possibilidade de atender alunos do ginásio e oferecer cursos especiais para alfabetização de adultos. Por fim, aponta que, de modo geral, os pais estavam satisfeitos com as atividades escolares dos seus filhos, ainda que $8 \%$ se ressentissem da falta de assistência médica, especialmente de dentistas e $5 \%$ considerassem o processo de alfabetização muito lento (Vasconcelos, I967: 4I).

Ainda que não possamos, por enquanto, reconstituir as atividades e orientações da Escola Experimental, essa pesquisa demonstra sua existência e a origem social de seus alunos. Tão rara a referência à Escola Experimental do Centro do Recife que Xavier (I999: I09), importante referência neste tema, 
suspeitava que apenas os Centros do Rio de Janeiro e da Bahia tiveram suas escolas. Rigorosamente, elas foram concebidas como o lugar da experimentação de programas de curso, métodos e recursos didáticos, funcionando como centros de aperfeiçoamento dos professores primários.

No Centro do Recife a DAM provavelmente se constituiu como uma importante unidade de formação e qualificação docente na cidade. As distinções e aproximações em relação à proposta do Centro de Cultura Popular devem ser analisadas em pesquisas futuras e nos darão pistas importantes sobre as formulações acerca da ação educacional no período.

\section{AS PESQUISAS EM DEBATE}

Após a compreensão das condições gerais de funcionamento do Centro do Recife, identificaremos parcialmente o conteúdo das pesquisas e dos debates que foram realizados no Centro durante a época que antecedeu a aprovação da LDB. Serão objetos de análise dois textos do primeiro número dos Cadernos Região e Educação. Nosso objetivo é conhecer melhor os possíveis nexos entre as pesquisas coordenadas por Freyre e o debate social sobre a LDB.

Com efeito, o texto que abre o número inaugural da revista é uma conferência realizada em novembro de 1959, de autoria do pesquisador Levy Cruz, cujo título é "Espaço, tempo, região e educação". A conferência foi realizada no período mais tenso da discussão sobre a LDB, quando houve o Movimento em Defesa da Escola Pública, após o lançamento do memorial dos bispos propondo que Anísio Teixeira fosse afastado do INEP e o lançamento do Manifesto dos Pioneiros novamente convocados (Fernandes, I966; Saviani, I996).

Levy Cruz trata do tema da regionalização e da municipalização da educação e nos dá pistas acerca da centralidade dada à escola como fator de mudança social. Apropriando-se de modo muito peculiar das ideias de Antonio Candido acerca da cultura caipira, Cruz constrói o argumento de que a municipalização das escolas primárias será bastante desfavorável porque professores da região rural - identificados com mores tradicionais - favorecerão a manutenção do status quo.

Para expor as razões da sua posição, Cruz elenca o que considera o repertório de costumes indesejáveis das sociedades rurais brasileiras: a) individualismo; b) apego a técnicas rotineiras e crenças obsoletas; c) conflitos políticos acompanhados de reações violentas; e d) diferenciação profunda na posição social entre os sexos com duplo padrão de moralidade sexual (bigamia masculina contrastando com a excessiva repressão das mulheres). Cruz expõe um quadro bastante negativo do mundo rural brasileiro, sugerindo que a educação assentada sobre valores rurais não apenas impedirá o desenvolvimento econômico, como também o desenvolvimento de uma cultura democrática. Com isso antevê que a municipalização do ensino primário - que 
seria então capitaneada por governantes e líderes locais, além de professores portadores dos costumes rurais - não possibilitará que a escola seja um fator de mudança social.

Outro argumento de Cruz é de que há uma tendência mundial de urbanização das áreas rurais. Cruz quase vaticina o fim do mundo rural, chamando a atenção para dados demográficos dos EUA, Europa, Nova Zelândia e Austrália. Conclui que, seguindo as tendências internacionais, o Brasil terá também áreas que serão rapidamente urbanizadas. A partir disso, propõe que o movimento demográfico seja acompanhado de um processo sociológico, no qual a escola desempenha papel fundamental, de difusão e adoção, por populações rurais, de valores e traços culturais oriundos dos centros urbanos. De acordo com o pesquisador, a escola precisa preparar alunos para a vida moderna e isso quer dizer que deve assumir o modo de vida urbano (Cruz, I96I: I5).

Para Cruz, o limite dos debates acerca da relação entre educação e região é que, em geral, ignoram o fator "tempo". Levar em conta o tempo significa, para ele, não ignorar o processo dominante que ocorre no período contemporâneo. Em período de acelerada urbanização e industrialização é preciso que a escola cumpra a tarefa de reorganizar os valores do campo aproximando-os dos urbanos. Apenas dessa maneira a escola seria um fator de mudança social favorável.

Por fim, o autor pede desculpas por apresentar ideias tão opostas às dos educadores. Afirma que a razão desta diferença de opiniões é porque sociólogos alcançam uma visão mais ampla e não estão limitados ao problema do ensino (Cruz, I96I: I7). Nesse sentido, podemos afirmar que, ainda que com argumentos sociologicamente discutíveis (até do ponto de vista da tradição paulista evocada, em especial os trabalhos de Antonio Candido), o mérito de Cruz é lançar uma dúvida sobre a vinculação, quase naturalizada por alguns educadores do período, entre descentralização do sistema de ensino e democratização da sociedade.

O texto de Cruz vem acompanhado da compilação do debate que ocorreu após a conferência. É então que se expressam as ideias de Gilberto Freyre, primeiro a tomar a palavra. Freyre comenta que Cruz desprezou totalmente um fenômeno chamado "rurbanização", que se refere a um processo social no qual os valores rurais não desaparecem, mas penetram nos valores urbanos. Freyre cita exemplos na Europa onde cidades mantêm a ambiência e a cultura rural, a despeito de seus intensos processos de urbanização. O debate segue com outras participações que, não obstante, apontam as supostas falhas do texto de Cruz: por um lado, a visão negativa em relação à cultura rural; por outro, a visão radical em relação ao processo de substituição da cultura rural pela cultura urbana.

As opiniões de Cruz são muito diferentes das ideias do diretor do Centro e esta é outra possível razão para a sua saída, em I962. Concepções acerca 
do mundo rural/mundo urbano e centralização/descentralização sustentadas por Cruz e Freyre são radicalmente distintas. No limite, podemos dizer que estão relacionadas a pressupostos muito diferentes acerca do tempo e do espaço. Para Cruz, o tempo é a superação do passado, ao passo que para Freyre passado, futuro e presente estão inexoravelmente articulados. Em Freyre, trata-se da noção de tempo tríbio, conceito que assumirá toda a sua forma em Ordem \& Progresso, obra publicada nesta época. As distinções sobre espaço são homólogas: para Cruz, o espaço rural está em vias de desaparecimento, ao passo que, para Freyre, rural e urbano serão sempre antagonismos vivos e presentes na vida social brasileira e é desejável que sejam equilibrados.

Para Freyre, a descentralização do sistema de ensino primário favoreceria um rompimento com o legado uniformizador do Estado Novo, permitindo uma forma de administração federativa que não apenas respeita a diversidade cultural nacional, mas também a dinâmica sociológica de conciliação dos contrastes, em particular, dos valores rurais e urbanos. Para Cruz, o rompimento com a solução varguista representa uma continuidade que impede a transformação da sociedade brasileira no sentido democrático; e a alternativa que se apresenta é entregar à União o controle do ensino primário possibilitando tirar do setor tradicional o controle sobre a formação de crianças e jovens.

O outro texto que compõe este volume é um relatório final de uma pesquisa sobre o "ajustamento emocional das professoras primárias do interior de Pernambuco". Seu autor, Paulo Rosas, submeteu a teste a opinião de que elevado índice de professoras primárias do Recife e que trabalham no interior de Pernambuco estão emocionalmente desajustadas. Rosas realiza uma sondagem que compreendeu a aplicação de 267 testes psicológicos entre professoras das escolas públicas primárias do interior do estado, cujo resultado o leva a confirmar que professoras casadas ou solteiras, jovens ou velhas, padecem de desajuste, mantendo, por vezes, uma relação bastante problemática com os alunos, seja por projetarem afetos maternais ou por recusarem os valores de origem dos estudantes. Os fatores de desajustes são muitos: estão fixadas num ambiente cujos valores não compartilham, onde não têm perspectivas de carreira, não são valorizadas, não têm bom salário e, mais grave no caso das solteiras, sofrem ainda de solidão. Rosas conclui, porém, que ainda que os resultados finais de sua pesquisa sejam melancólicos, sente-se entusiasmado pela ideia da rurbanização, termo cunhado por Gilberto Freyre e que possibilita pensar de um modo novo a relação entre o meio rural e o meio urbano (Rosas, I96r: 64).

Se o texto de Cruz coloca em dúvida a municipalização do ensino primário devido à possibilidade de reprodução de valores tradicionais indesejáveis na escola primária, o segundo texto recomenda a municipalização concluindo que o desajustamento das professoras primárias das cidades ao 
ambiente rural coloca em risco projetos de educação regional. De um lado, a municipalização reforçaria traços de atraso cultural, de outro, as condições da carreira docente favoreceriam desajustes sociais e emocionais que seriam transmitidos aos alunos. Está, portanto, posto um dilema entre a igualdade e a universalização e o ajustamento e a particularização. Em ambos os casos, a noção de rurbano é entendida como expressão de um novo acordo entre a tradição e a modernidade, mobilizada não apenas como recurso analítico, mas principalmente como devir.

\section{APONTAMENTOS FINAIS}

A análise das condições de funcionamento do Centro do Recife e a identificação parcial do conteúdo das investigações e dos debates que surgiram ali possibilitam não apenas o entendimento de situações muito particulares da atuação de Gilberto Freyre, mas também a compreensão das nuances e impasses fundamentais no período, em especial os nexos e tensões constitutivas das tarefas de elaboração de um projeto educacional nacional.

Um aspecto importante que convém observar é que, no CBPE e nos Centros Regionais, os impasses sobre a definição do sistema educacional do Brasil se traduziram também em seus próprios dilemas organizacionais. Ironicamente, O CBPE - que postulava estudos específicos para diagnóstico e proposição de uma nova forma regionalizada do sistema educacional brasileiro - era centralizador em sua forma de gestão.

Esta investigação nos leva a considerar dois momentos do Centro do Recife. O primeiro, de interesse pelas pesquisas sociais que, ainda que estivessem sob o escrutínio do CBPE, tiveram por base estudos de comunidade e de unidades empíricas menores (como as famílias), além das manifestações de cultura popular. Do ponto de vista material, foram anos de formação do patrimônio do Centro, mas de dificuldades para estabilização do quadro de pesquisadores. No segundo momento, após a aprovação da LDB, houve desligamento definitivo de pesquisadores, fim das pesquisas sociais, ampliação dos serviços de aperfeiçoamento docente acompanhada da definição de uma nova agenda de pesquisas educacionais aplicadas. Foi um período de parcerias com a Sudene e com o Governo do Estado, e de financiamento da USAID para desenvolver pesquisas e ações com a finalidade de esboçar alternativas educacionais para o desenvolvimento da região Nordeste que fossem previstas no Plano Nacional de Educação.

O projeto original do CBPE se apresentava, para Freyre, como algo interessante do ponto de vista de suas afinidades intelectuais. A agenda de pesquisas do DEPS no Centro do Recife é sugestiva nesse sentido. Basta ver os temas: formas de transmissão de cultura oral, controle das crianças na intimidade familiar e o modo de vida de jangadeiros, para citar alguns exem- 
plos. Os temas sugerem, com efeito, uma perspectiva que valoriza e indaga acerca das modalidades não formais de educação: as palavras, a família e a comunidade. É, pois, nesse sentido, conhecida sua afirmação que não considerava a alfabetização tão fundamentalmente necessária, sobretudo em sociedades rurais:

Certos autores, dos que se ocupam superficialmente dos problemas de cultura, mostram especial tendência para exagerar a importância da alfabetização, como sinal de superioridade absoluta dos povos considerados civilizados sobre os rústicos (Freyre, 2001: 88).

Para Freyre, as ações em favor da educação ultrapassam a orientação escolar e, por vezes, as dispensam - especialmente se a difusão dos conhecimentos escolares tiver por efeito o sacrifício da diversidade cultural. Nesse sentido é que considerou a regionalização do sistema educacional uma alternativa compatível com a coexistência de diferenças sociais, étnicas e culturais. Segundo seu argumento, a regionalização dos métodos e conteúdos escolares atuaria em favor do pluralismo, sempre vantajoso para a sociedade.

Nesse sentido, segundo Freyre, uma das principais tarefas do Centro seria não apenas a identificação da diferenciação sociocultural das regiões politicamente definidas, mas também, através de estudos sociológicos mais minuciosos, a diferenciação interna das áreas delimitadas. Esse mapeamento seria um subsídio fundamental para a definição de um plano educacional para a região Nordeste capaz de manter suas especificidades: uma política de alfabetização convergente com os valores locais.

Com efeito, o autor temia, por um lado, ações que homogeneizassem o país, mas, por outro, denunciava o perigo de que a diferenciação econômica entre o Sul e o Norte (que ele traduz também como "mundo rural" e "urbano") se tornasse ameaçadora para a unidade nacional. Inspirado nestes temores, nos anos de 1950 e I960 produziu textos e ministrou palestras procurando demonstrar que o que ele chama de "choque entre o Brasil rural e o Brasil urbano" exigia o esforço de integração através, principalmente, do deslocamento de indústrias para o Nordeste, mas também da identificação e do reconhecimento da positividade da pluralidade étnica e cultural do país (Freyre, I968: 99). O que ele propunha era, rigorosamente, um equilíbrio sofisticado entre diversidade e desenvolvimento econômico. A ação educacional deveria então ser uma das ações capazes de contribuir para esta engenharia social.

Os confrontos entre diferentes perspectivas acerca destes dilemas se expressam nos debates que ocorriam no Centro. Tivemos a possibilidade de consultar ao primeiro número da revista Cadernos Região e Educação. Os dois principais textos ali publicados, em conjunto, acabam por compor uma visão interessante acerca das interpretações do período. Os debates articularam impasses relativos à centralização e descentralização do ensino primário, acionando representações sociais de tempo (passado e futuro) e espaço (rural e urbano). 
Cruz afirmava que a organização primária descentralizada resultaria na formação de uma mentalidade pouco democrática porque próxima aos hábitos rurais, ao passo que Rosas sugeria que a educação primária, nas condições dadas pela carreira docente, resultava não apenas na inadaptação das professoras urbanas ao meio rural, mas a transmissão desta condição aos alunos, que tenderiam, com isso, a não valorizar as coisas de seu ambiente de origem. Os textos demonstram uma oscilação entre duas perspectivas: uma que preza pela igualdade e outra que opera sob o registro da adaptação social. Num texto, os termos "rural" e "atraso" estão alinhados exigindo centralização e universalização da experiência urbana. No outro, há um diagnóstico da inadaptação que reclama uma política de carreira docente e de organização do sistema escolar mais afinadas com as particularidades do meio rural. O recurso ao conceito de rurbano, mobilizado no debate do primeiro texto e no corpo do segundo texto, se apresenta, então, como uma engenharia política que propõe o reconhecimento e manutenção das culturas diversas, porém integradas em condições econômicas mais ou menos semelhantes.

Rigorosamente, o conceito de rurbano revela que a interpretação de Freyre estava tensionada em dois pontos fundamentais: a) não é possível tratar as diferenças regionais, tão simplesmente, como "diversidades" e "pluralidades", pois, conforme afirmava, as distinções econômicas entre as regiões tornavam-se tão divergentes quanto arriscadas para o equilíbrio nacional; b) as questões postas exigiam, para Freyre, a celebração de um novo pacto entre as regiões, atitude reclamada como decisiva num momento em que os mecanismos de autocontrole da sociedade foram ameaçados e exigiam uma nova engenharia social, capitaneada pelos cientistas sociais.

A descentralização educacional aparece, então, como um imperativo dessa nova engenharia provocada (Freyre, I968: I00). Ele afirmava, com efeito, que a educação não tem apenas como finalidade a aceleração, mas também a correção e, sobretudo, o equilíbrio do desenvolvimento (Freyre, I968: I29). Nesse sentido, a definição da ação educacional parece articular dramaticamente o impasse entre desenvolvimento e diversidade além de, sob a forma da centralização e descentralização, acionar uma discussão sobre a natureza do pacto nacional.

Acreditamos, por isso, ser importante, em trabalhos futuros, apontar as possíveis tensões entre as ideias de desenvolvimento que portavam algumas agências parceiras de Freyre nos projetos do Centro do Recife (como a Sudene e a USAID, por exemplo) e a concepção de luso-tropicalismo que ele então formulava.

Com efeito, o exame da atuação institucional de Freyre nos permite formular hipóteses que visam compreender melhor os dilemas deste autor, especialmente os impasses enfrentados pela sua interpretação acerca das condições de mudança social no Brasil, posta verdadeiramente a teste neste período. 
Em termos mais práticos, o Gilberto Freyre que surge na consulta a esta documentação é um burocrata dedicado, que lia atentamente as Portarias, fazia anotações em suas margens, além de controlar a prestação de contas. Era também exigente e implacável em suas demandas para o Estado, ao mesmo tempo em que articulava com êxito outras modalidades de financiamento.

Essa dimensão de sua trajetória nos mostra que o debate parlamentar acerca da definição de uma lei geral para educação no Brasil e, depois, as pressões internas para a planificação e externas para o controle ideológico da região, foram favoráveis para um determinado tipo de realização institucional. Provavelmente, o Centro do Recife tornou-se um de seus principais recursos institucionais (além do Instituto Joaquim Nabuco), algo decisivo em sua trajetória de cientista social independente da universidade.

Outro ponto importante que vale a pena destacar é que possivelmente o Recife se tornou, naquela época no Brasil, o principal epicentro de disputas educacionais. Há, de acordo com os dados aqui levantados, uma trama institucional interessante que envolve, além do Centro do Recife, a Prefeitura Municipal, a Sudene e a USAID - instituições que se dedicaram a investir e atuar no campo educacional, especialmente no ensino primário. Isso nos leva a crer que a compreensão do debate e das ações educacionais que se realizaram ali tem valor heurístico para deslindar as alternativas e as consciências possíveis da sociedade nesta época. Nesse sentido, esses dados que acabamos de demonstrar apontam para futuras análises que ultrapassam a contribuição de Gilberto Freyre, ao mesmo tempo em que o situam numa nova dimensão contextual pouco explorada.

Sintetizamos aqui a análise de alguns aspectos da documentação que nos permitem identificar as condições básicas de funcionamento do Centro do Recife. Há, porém, novas questões que exigem aprofundamento:

a) o estudo da trajetória dos pesquisadores que trabalharam no Centro;

b) a compreensão dos arranjos institucionais que, no Recife, se ocuparam com ações no campo educacional - em particular, partidos políticos, agências externas e movimentos sociais e suas diversas percepções acerca da natureza e da finalidade da ação educacional;

c) a natureza da agenda de atividades do Centro do Recife e seus nexos com esses arranjos institucionais e com os escritos de Freyre no mesmo período.

O desenvolvimento destas novas frentes de análise permitirá identificar, a partir das disputas no campo educacional no Recife, os projetos sociais delineados antes da interrupção da experiência democrática, especialmente aqueles formulados por intelectuais como Gilberto Freyre, cujo apoio ao Golpe Militar foi conhecido. ${ }^{33}$ 
Simone Meucci é doutora em Sociologia pela

Universidade Estadual de Campinas (Unicamp) e professora de sociologia na Universidade Federal do Paraná (UFPR), onde coordena grupo de estudos sobre pensamento social e realiza pesquisas sobre história e ensino da sociologia no Brasil. É autora dos livros Institucionalização da sociologia no Brasil: primeiros manuais e cursos (20II) e Artesania da sociologia no Brasil:

contribuições e interpretações de Gilberto Freyre (2015). 


\section{NOTAS}

I Agradeço a Cristiane Pires pelo apoio para digitalização dos microfilmes e aos funcionários do CEDOPE, laboratório do Departamento de História da Universidade Federal do Paraná (UFPR), cuja infraestrutura foi indispensável para a análise dos documentos.

2 Portaria $\mathrm{n}^{\circ} 377$, assinada pelo diretor do INEP, Anísio Teixeira, de 3/ıo/ı957.

3 Ofício $n^{\circ} 3 / 57$, no qual Freyre informa Anísio Teixeira de que assumiu o cargo, de 29/10/1957

4 Discurso de Gilberto Freyre a propósito da Inauguração do Centro Regional do Recife, em I8/ir/ı957. Acervo de microfilmes da Fundação Joaquim Nabuco.

5 Discurso de Gilberto Freyre a propósito da Inauguração do Centro Regional do Recife, em I8/ıi/r957. Acervo de microfilmes da Fundação Joaquim Nabuco.

6 Ofício n ${ }^{\circ}$ 44/58 de Gilberto Freyre a Anísio Teixeira. Acervo de microfilmes do Instituto Joaquim Nabuco.

7 Carta informal de Gilberto Freyre para Anísio Teixeira, de 28/II/I957. Acervo de microfilmes da Fundação Joaquim Nabuco.

8 Resenha Histórica. Cadernos Região e Educação, 3/6, dez., I963.

9 Resenha Histórica. Cadernos Região e Educação, 3/6, dez., I963, p. 5 .

Io Os Centros Regionais tiveram suas atividades encerradas entre os anos de 1972 e I975. Já as atividades do Centro Brasileiro de Pesquisas Educacionais foram definitivamente encerradas em 1977.

I I Ofício $n^{\circ}$ I7/57 de Gilberto Freyre para Anísio Teixeira, de 5/II/I957. Acervo de microfilmes da Fundação Joaquim Nabuco.

I2 Relação do pessoal administrativo do Centro Regional do Recife do ano de 1959. Acervo de microfilmes da Fundação Joaquim Nabuco.

I3 Levy Cruz fez estudos na Escola Livre de Sociologia e Política sob orientação de Donald Pierson no final dos anos de I940. Estudou também na Universidade de Chicago.

I4 Consultamos os números dos Cadernos Região e Educação publicados até I968, de modo que não sabemos por quan- 
to tempo a revista circulou. Ela segue o padrão visual das publicações do CBPE e é composta por duas seções: a primeira consiste num bloco de dois textos resultantes de estudos exploratórios, relatórios de pesquisas ou textos de conferências. A segunda parte compreende uma ou duas resenhas de livros estrangeiros sobre educação. A revista é uma importante fonte a partir da qual é possível reconstituir as atividades do Centro e seus conteúdos. No período consultado, observamos que sua periodicidade foi mantida em dois volumes ao ano.

I5 Esta tarefa ficou sob responsabilidade da Divisão de Documentação e Informação Pedagógica (DDIP) do CBPE, órgão que lançou, pouco tempo após a criação do CBPE, um Boletim (com periodicidade mensal) e a revista Ciências Sociais e Educação (com periodicidade quadrimestral). Estes periódicos faziam parte de uma rede de publicações cuja distribuição atingia desde o professor até os órgãos internacionais. Segundo Gouveia (2008), os impressos do CBPE tinham um papel central na intenção de articular e legitimar as estratégias de um grupo que mantinha uma certa visão da educação.

I6 Ofício n 455/I96o de Anísio Teixeira para Gilberto Freyre, de I7/03/I960. Acervo de microfilmes da Fundação Joaquim Nabuco.

I7 Carta de Anísio Teixeira para Gilberto Freyre, de 30/04/I962. Acervo de microfilmes da Fundação Joaquim Nabuco.

I8 Agenda da Primeira Reunião Consultiva do Centro Brasileiro de Pesquisa Educacional, de 4 a 7/7/1957. Acervo de microfilmes da Fundação Joaquim Nabuco.

I9 A Aliança para o Progresso foi um programa de financiamento estadunidense para favorecer investimentos de desenvolvimento da América Latina. Foi apresentado em I96I, no Uruguai, durante sessão extraordinária do Conselho Interamericano Econômico no Uruguai, em documento que ficou mais conhecido como "Carta de Punta del Este". Sua administração foi confiada à United States Agency for International Development (USAID), criada também em I96I para definir programas de assistência externa de caráter civil.

20 Esse acordo de apoio do governo dos EUA à Sudene tem como fundamento a ideia de que o Nordeste brasileiro era 
uma área de risco. A pobreza e a atuação das Ligas Camponesas foram consideradas sinais da iminência de revoltas que podiam ser potencialmente favoráveis à expansão do comunismo. A USAID instalou uma unidade administrativa no Recife com a finalidade de administrar os seus investimentos no local (Ribeiro, 20068: 135).

2I A Segunda Conferência sobre Educação e Desenvolvimento Econômico e Social na América Latina foi organizada pela Unesco, a Cepal, a OIT, a FAO e a OEA para definir um plano decenal de educação para a região. A Conferência recomendou prioridade ao planejamento da educação, aos métodos de avaliação de custos e benefícios, à elaboração de métodos diagnósticos da situação socioeconômica e educacional e às técnicas de investigação das necessidades educacionais relacionadas ao desenvolvimento econômico e social (Freitas, 2005: 88).

22 Resenha Histórica. Cadernos Região e Educação, 3/6, dez., I963, p. I I.

23 Há estudos que apontam que algumas divergências significativas entre Furtado e os interesses da USAID tornaram o campo de ação da agência internacional bastante tenso e limitado. Nesse sentido, para atuar mais livremente, a USAID se utilizava também do expediente de celebrar acordos diretos com os governadores nordestinos (Ribeiro, 2006: 46).

24 Este estudo em particular fazia parte de um programa de pesquisas elaborado por Darcy Ribeiro no CBPE a fim de mapear as diversidades regionais a partir do estudo de "cidades laboratório" que contemplassem as condições de existência de determinadas áreas do país (Xavier, I989: 156).

25 O MCP era uma entidade civil que, não obstante, assumiu funções de Secretaria Municipal de Educação, realizando programas de educação infantil, alfabetização de adultos e ações culturais (Teixeira, 2008: 130).

26 Ofício $n^{\circ}$ 5 $1 / 63$ de Anísio Teixeira a Gilberto Freyre, de Io/I/I963. Acervo de microfilmes da Fundação Joaquim Nabuco.

27 Freston (I989: 333) cita, em sua análise sobre o Instituto Joaquim Nabuco, dificuldades semelhantes. E esse não parece ser fenômeno exclusivo do Recife: Ferreira (2006: 
I96) observa que, no mesmo período, no Centro Regional de São Paulo, ocorreu o desligamento de Renato Jardim Moreira e Dante Moreira Leite, insatisfeitos com a instabilidade, o trabalho exigente e a centralização excessiva de poder.

28 Cadernos Região e Educação, 3/5, jun., I963.

29 Cadernos Região e Educação, 4/7 e 8, jul. e dez., I964.

30 Carta de Anísio Teixeira a Gilberto Freyre, de Io/o6/ıg62. Acervo de microfilmes da Fundação Joaquim Nabuco.

3I Carta de Anísio Teixeira a Gilberto Freyre, de iı/or/Ig63. Acervo de microfilmes da Fundação Joaquim Nabuco.

32 Resenha Histórica. Cadernos Região e Educação, 3/6, dez. I963, p. II.

33 Sobre o apoio de Freyre ao Golpe Militar, ver o prefácio de Brasis, Brasil, Brasília (I968).

\section{REFERÊNCIAS BIBLIOGRÁFICAS}

Abreu, Alzira Alves. (2008). Revisitando os anos I950 através da imprensa. In: Botelho, André; Bastos, Elide Rugai \& Villas Bôas, Glaucia (orgs.). O moderno em questão: a década de I950 no Brasil. Rio de Janeiro: Topbooks, p. 2 I I-235. Barbosa, Igor Andrade Vidal. (2010). A governamentalidade e o desenvolvimento internacional: um estudo de caso do acordo do Nordeste de 1962. Dissertação de mestrado. Pontifícia Universidade Católica do Rio de Janeiro.

Bastos, Elide Rugai. (I984). As ligas camponesas. Rio de Janeiro: Vozes.

Consorte, Josidelth Gomes. (I997). Culturalismo e educação nos anos 50: o desafio da diversidade. Cadernos CEDES, I8/43, p. 26-37.

Corrêa, Marisa. (1989). A antropologia no Brasil, I960-I980. In: Miceli, Sérgio (org.). História das Ciências Sociais no Brasil. São Paulo: Vértice/Ed. Revista dos Tribunais/IDESP, p. 25-Io6, (vol. 2).

Cruz, Levy. (I96I). Espaço, tempo, região e educação. Cadernos Região e Educação, I/I, p. 4-47.

Fernandes, Florestan. (I966). Educação e sociedade no Brasil. São Paulo: Dominus/Edusp. 
Freitas, Dirce Nei. (2005). A avaliação educacional como objeto de recomendações internacionais. Estudos em Avaliação Educacional, I6/31, p. 79-ıоo.

Freitas, Marcos Cézar de. (200I). História, antropologia e a pesquisa social: itinerários intelectuais. Campinas: Cortez.

Ferreira, Márcia Santos. (2008). Os Centros de Pesquisas Educacionais do INEP e os estudos em ciências sociais sobre a educação no Brasil. Revista Brasileira de Educação, I3/38, p. 279-4II.

Ferreira, Márcia Santos. (2006). Centros de Pesquisas do INEP: pesquisa e política educacional entre as décadas de I950 e I970. Tese de Doutorado. FFLCH/Universidade de São Paulo.

Freston, Paul. (1989). Um império na província. In: Miceli, Sérgio (org.). História das Ciências Sociais no Brasil. São Paulo: Vértice, Editora Revista dos Tribunais, IDESP, p. 3I6-358. Freyre, Gilberto. (200I). Interpretação do Brasil. São Paulo: Companhia das Letras.

Freyre, Gilberto. (I968). Brasis, Brasil, Brasília. Rio de Janeiro: Record.

Freyre, Gilberto. (1958). Integração portuguesa nos trópicos. Portugal: Junta de Investigações do Ultramar.

Freyre, Gilberto. (I953). Um brasileiro em terras portuguesas. Rio de Janeiro: José Olympio.

Gonçalves, Mauro Castilho. (1996). Uma incursão nas relações entre ciências sociais e educação em São Paulo através da Revista Pesquisa e Planejamento (I957-I966). Dissertação de mestrado. Pontifícia Universidade Católica de São Paulo. Gouvêa, Fernando César Ferreira. (2008). Tudo de novo no front: o impresso como estratégia de legitimação do Centro Brasileiro de Pesquisas Educacionais (1952-I954). Tese de doutorado. PPGE/Pontifícia Universidade Católica do Rio de Janeiro.

Larreta, Enrique R. \& Giucci, Guillermo. (2007). Gilberto Freyre: uma biografia cultural. Rio de Janeiro: Civilização Brasileira.

Mariani, Maria Clara. (I982). Educação e ciências sociais: o INEP. In: Schwartzman, Simon (org.). Universidades e instituições científicas no Rio de Janeiro. Brasília: CNPq. 
Mendonça, Ana Valeska \& Xavier, Libânea Nacif. (2008). O INEP no contexto das políticas do MEC - I950-I960. In: Mendonça, Ana Valeska \& Xavier, Libânea Nacif (orgs.). Por uma política de formação do magistério nacional: o INEP/ MEC dos anos 1950/1960. Brasília: Instituto Nacional de Pesquisas Educacionais Anísio Teixeira, p. 19-38.

Meucci, Simone. (20I5). Artesania da sociologia no Brasil: contribuições e interpretações de Gilberto Freyre. Curitiba: Appris. Montalvão, Sérgio Sousa. (20II). Por uma história política da educação: a Lei de Diretrizes e Bases e a democracia na Terceira República (I946-I96I). Tese de doutorado. PPG/ CPDOC-Fundação Getulio Vargas.

Neves, Clarissa Eckert Baeta. (2002). Estudos sociológicos sobre educação no Brasil. In: Miceli, Sérgio (org.). O que ler nas ciências sociais no Brasil. São Paulo/Brasília: Anpocs/ Sumaré/Capes.

Pallares-Burke, Maria Lucia. (2005). Gilberto Freyre: um vitoriano nos trópicos. São Paulo: Ed. Unesp.

Pallares-Burke, Maria Lucia \& Burke, Peter. (2009). Repensando os trópicos: um retrato intelectual de Gilberto Freyre. São Paulo: Ed. Unesp.

Paoli, Niuvenius. J. (1995). As relações entre as ciências sociais e educação nos anos 50/60 a partir das histórias e produções intelectuais de quatro personagens: Josidelth Gomes Consorte, Aparecida Joly Gouveia, Juarez Brandão Lopes e Oracy Nogueira. Tese de doutorado. FFLCH/Universidade de São Paulo. Peregrino, Maria Graziela. (1987). Gilberto Freyre, orientador e diretor do CRPE do Recife. Ciência \& Trópico, I5/2, p. 205-2I3. Disponível em <http://www.bvgf.fgf.org.br/ frances/critica/artigos/art_cient/orientador.htm>. Acesso em 27 jun. $201 \mathrm{I}$.

Ribeiro, Ricardo Alaggio. (2006). A Aliança para o Progresso e as relações Brasil-Estados Unidos. Tese de doutorado. IFCH/ Universidade Estadual de Campinas.

Rosas, Paulo. (I96I). Ajustamento emocional das professoras primárias no interior de Pernambuco. Cadernos Região e Educação, I/ı, jun., p. 49-72.

Saviani, Dermeval. (I996). Florestan Fernandes e a educação. Estudos Avançados, Io/26, p. 7I-87. 
Saul, Renato P. (2004). As raízes renegadas da teoria do capital humano. Sociologias, 6/12, jul./dez., p. 230-273.

Teixeira, Anísio. (I953). A educação e a crise brasileira. Revista Brasileira de Estudos Pedagógicos, 19/50, p. 20-43.

Teixeira, Anísio. (1952). Discurso de posse do professor Anísio Teixeira no Instituto Nacional de Estudos Pedagógicos. Revista Brasileira de Estudos Pedagógicos, I7/46, p. 69-79. Teixeira, Wagner da Silva. (2008). Educação em tempos de luta: história dos movimentos de educação e cultura popular (I958-I964). Tese de doutorado. ICHF/Universidade Federal Fluminense.

Xavier, Libânea Nacif. (I999). O Brasil como laboratório: educação e ciências sociais no projeto dos Centros Brasileiros de Pesquisas Educacionais, CBPE/INEP/MEC (I950I960). Bragança Paulista: Edusf.

Vasconcelos, Myrian Brindeiro de Moraes. (1967). Tipo de família dos alunos da escola do CRPER. Cadernos Região e Educação, 7/14, p. 3-47.

Weber, Silke. (1984). Política e educação: o Movimento de Cultura Popular no Recife. Revista de Ciências Sociais, 27/2, p. 233-262. 
Palavras-chave

Centro de Estudos Educacionais do Recife;

Gilberto Freyre; Anísio Teixeira; Pensamento social; Educação

Keywords Regional Center for Educational Studies of Recife; Gilberto Freyre; Anísio Teixeira; Social thought; Education.

\section{GILBERTO FREYRE NO COMANDO DO CENTRO REGIONAL DE PESQUISAS EDUCACIONAIS DO RECIFE: EDUCAÇÃO EM DEBATE (1957-1964)}

\section{Resumo}

Neste artigo examinamos as condições de funcionamento do Centro Regional de Estudos Educacionais do Recife, especialmente entre os anos de 1957 e I964. O Centro do Recife, como ficou conhecido, esteve sob a direção de Gilberto Freyre. Sua análise permite compreender uma nova dimensão, pouco conhecida, da atuação deste intelectual: a coordenação de pesquisas sociológicas e educacionais, a oferta de cursos de formação de professores e a gestão de uma Escola Experimental. Esta análise demonstra que o Centro do Recife foi bastante ativo, favorecido, por um lado, pelas afinidades entre Gilberto Freyre e Anísio Teixeira e por outro, por condições particulares da política internacional, que permitiram recursos para atividades de formação do magistério e pesquisas aplicadas.

\section{GILBERTO FREYRE IN CHARGE OF THE REGIONAL CENTER FOR EDUCATIONAL STUDIES OF RECIFE: EDUCATION UNDER DEBATE (1957-1964)}

\section{Abstract}

This paper examines the operating conditions of the Regional Center for Educational Studies of Recife, especially from I957 to I964. The Center of Recife, as it became known, was directed by Gilberto Freyre. The analysis stresses a new dimension of Freyre's performance: the coordination of sociological and educational research, the provision of teaching training courses and the management of an Experimental School. It shows that the Center of Recife was very active, favored by the affinities that existed between Gilberto Freyre and Anísio Teixeira and also by particular conditions of international politics, which provided funding for teaching training and applied researches. 